\title{
Measuring the Cost- Effectiveness of Clean Vehicle Subsidies
}

Tamara Sheldon and Rubal Dua 


\section{About KAPSARC}

The King Abdullah Petroleum Studies and Research Center (KAPSARC) is a non-profit global institution dedicated to independent research into energy economics, policy, technology and the environment, across all types of energy. KAPSARC's mandate is to advance the understanding of energy challenges and opportunities facing the world today and tomorrow, through unbiased, independent, and high-caliber research for the benefit of society. KAPSARC is located in Riyadh, Saudi Arabia.

\section{Legal Notice}

(C) Copyright 2018 King Abdullah Petroleum Studies and Research Center (KAPSARC). No portion of this document may be reproduced or utilized without the proper attribution to KAPSARC. 


\section{Key Points}

emand-side policies, including rebates, sales tax exemptions, and tax credits promote clean vehicle adoption, with the goal of reducing local air pollution and greenhouse gas (GHG) emissions. Limited research to date on their cost-effectiveness and efficiency suggests such subsidies are unsustainably expensive, but this may not tell the whole story. KAPSARC used a nationally representative sample of new car purchases in the United States and developed a vehicle choice model-based simulation to assess the scope for reducing the costs of subsidy policies. Simulation results suggest that:

The existing federal incentive schedule for plug-in electric vehicles (PEVs) is expensive, $\sim \$ 35,601$ per additional PEV. However, this figure may not represent the true cost of the subsidy policy. Its costeffectiveness could more than double by targeting incentives based on consumer income, vehicle disposal, geography, and/or vehicle miles traveled.

Policymakers have the scope to improve the policy cost-effectiveness by opting for more targeted subsidies, perhaps less than $\$ 15,000$ per PEV, restricted to individuals with annual incomes under $\$ 70 \mathrm{k}$. This is because such consumers may not purchase a new PEV in the absence of subsidies. However, such an approach would require a countervailing policy to prevent unintended distortions in the used car market arising from such progressively targeted subsidy design.

Giving similar levels of subsidies to plug-in hybrid electric vehicles (PHEVs) and battery electric vehicles (BEVs) would result in a similar reduction in gasoline consumption but at a slightly lower marginal cost compared to assigning higher subsidies to BEVs.

Existing federal subsidy structure involving larger subsidies for high range BEVs results in greater BEV adoption. Such practice might remain prevalent given the policymakers' goal to reach sufficient adoption levels of high range BEVs to warrant 'economies of scale' in the production of larger batteries.

A 100-mile improvement in BEV driving range at the same cost as today's offerings is sufficient for a fixed subsidy policy to become as cost-effective as the best-targeted subsidy schedule without any range improvements. However, improvements in BEV driving range, coupled with targeted subsidies could deliver a more than three-fold improvement in policy cost-effectiveness. 


\section{Executive Summary}

M any cities, states, and countries subsidize plug-in electric vehicles (PEVs) to help meet environmental goals such as reduced local air pollution and carbon dioxide emissions. Subsidies take various forms, including rebates, sales tax exemptions, and tax credits. Despite the prevalence of PEV subsidies, research into their cost-effectiveness and efficiency is limited. Furthermore, policymakers have not typically tested the effectiveness of these subsidies. Stated-preference research suggests that targeting 'marginal' consumers who are 'on the fence,' or could be nudged to purchase a PEV with a subsidy, can reduce the costs of such demandside policies.

This study assesses the scope for reducing the costs of existing subsidies for PEV sales, through examining the feasibility of a more targeted approach. It also measures the impact of changes in vehicle offerings, specifically the driving range of battery electric vehicles (BEVs), on the potential costs of a fixed subsidy schedule. We employed a vehicle choice model for this purpose using nationally representative, revealed preference survey data of new vehicle buyers in the United States (U.S.). The study uses this model to make predictions for the market share of PEVs and fleet gasoline consumption under alternative subsidy policies. The study also used the demographics and attitudinal elements of the survey data to incorporate consumer heterogeneity into the vehicle choice model. We use the latter, which includes income, vehicle disposal type, geography, and vehicle miles traveled, to explore various subsidy policy designs.

The results of this study suggest that the existing federal subsidy structure accounted for only 17 percent of PEV sales in the 2015 model year. This would mean that the cost of existing incentives per additional PEV purchase is very high, at around $\$ 35,601$, with the cost per gallon of gasoline saved at $\$ 8.18$ per gallon. A more targeted approach to subsidy policy design would give policymakers the scope to improve the impact and reduce the costs of these subsidies. This research shows that, in every simulation, the most cost-effective scenario is to limit subsidies to lower-income individuals: those with annual incomes under $\$ 70 \mathrm{k}$. Such a scenario would mostly restrict subsidies to those consumers who would not have otherwise purchased a PEV (85-95 percent of subsidy dollars) and would account for around 30 percent of PEV sales. The policy cost per additional PEV would be limited to around $\$ 16,000$, and the cost per gallon of gasoline savings would fall to $\$ 3.55$ per gallon. Furthermore, the cost reductions from an improvement in the driving range of BEVs by 100 miles could equal those of a targeted subsidy. This study predicts that targeted subsidies, combined with an improvement in vehicle range, would limit the policy cost per additional BEV to $\$ 9,712$ and the cost per gallon of gasoline to $\$ 2.41$ per gallon.

A real-world example of targeted subsidy design is California's Replace your Ride pilot program that restricts subsidies to low-income consumers. However, it is important to note that such targeted subsidy designs have the potential to distort the used car market. Appropriate measures would have to be put in place to avoid such unintended consequences.

Targeted subsidy designs will differ depending on their goal. Policymakers could restrict subsidies to low-income individuals if the aim is to maximize PEV market share. Alternatively, if their goal is to minimize gasoline consumption, policymakers 
might limit subsidies to individuals who dispose of a large conventional vehicle, who reside in rural or farming areas, or who drive more than 2,000 miles per month.

Current U.S. federal policy subsidizes the purchase of PEVs on a sliding scale relative to their battery capacities. This study finds that maintaining this approach for purchases of BEVs would increase their sales. Policies that do not subsidize according to battery capacity would result in greater plug-in hybrid electric vehicle (PHEV) adoption. Thus, given policymakers' goal of encouraging the development of longer-range batteries for BEVs, they are likely to continue assigning larger subsidies to BEVs. However, the level of reduction in gasoline consumption is the same in both the cases, with a slightly lower marginal cost when BEVs and PHEVs are equally subsidized. Thus, if the policy goal is to minimize local air pollution and GHG emissions at lower near-term cost, there is no benefit in prioritizing one technology over the other. 
overnments in many countries offer subsidies for plug-in electric vehicles (PEVs), including battery electric vehicles (BEVs) and plug-in hybrid electric vehicles (PHEVs). France, Sweden, the United Kingdom, China, and various Canadian provinces offer PEV rebates varying from $\$ 3,450$ to $\$ 8,500$. Norway, the Netherlands, France, Denmark, the United Kingdom (U.K.), and China also have substantial tax exemptions for PEV purchases/registrations. In the United States (U.S.), PEV purchases qualify for a federal income tax credit of up to $\$ 7,500$, depending on battery capacity: the larger the battery capacity, the larger the credit. Many states also offer additional PEV subsidies such as rebates, tax credits, and sales tax exemptions.

Evidence suggests there are three consumer segments in the PEV market: those who are early adopters and keen to purchase PEVs, those who are highly unlikely to consider a PEV even with a large subsidy, and those who would consider purchasing PEVs depending on price and attributes (Sheldon, DeShazo, and Carson 2017). Subsidizing the first segment is expensive and seemingly unnecessary. Stated-preference research suggests policymakers have the scope to reduce the cost of adoption policies by targeting resources at the third segment, i.e., those 'marginal' consumers who are 'on the fence' or could be nudged to purchase a PEV with a subsidy.

Searle and Lutsey (2014) monetize the total direct and indirect state-level subsidies in the U.S. and use regression techniques to find that a 10 percent increase in subsidies leads to an increase in BEV sales of just 1.8 percent. Sierzchula et al. (2014) also use regression methods to examine the relationship between consumer subsidies and national PEV market share in 30 countries. They find a positive correlation between subsidies and PEV adoption rates. Tal and Nicholas (2016) employ a stated preference survey of PEV buyers in eleven U.S. states. Their results attribute more than 30 percent of PEV sales to the federal tax credit. Li et al. (2017) use a stylized model with indirect network effects and a panel of quarterly metropolitan statistical area-level PEV sales in the U.S., to investigate the role of subsidies in PEV sales and the impact of feedback loops. They find that from 2011 to 2013,40 percent of PEV sales resulted from the federal tax credit, but that 40 percent of those, in turn, came from feedback loops; in particular, the availability of charging stations. They conclude that the budget would have been twice as effective in establishing PEV sales had it been spent on charging stations instead of subsidizing PEV purchases.

This paper evaluates the scope for reducing the costs of subsidy policies through an analysis of different PEV subsidy structures. The study uses a large, individual-level dataset on actual vehicle purchases, rather than aggregate market share or stated preference data. This allows the estimation of a detailed vehicle choice model to characterize individual-level purchase decisions. 


\section{Data}

his study relies on data from a largescale, nationally representative revealed preference survey of new car buyers. The dataset matches the vehicle identification numbers in the 2015 New Vehicle Experience Study (NVES) conducted by Strategic Vision Inc. with Edmunds' database of vehicle characteristics.
Similar to Sheldon and Dua (2018), this study utilizes three sets of elements from this merged dataset: household demographics, consumer attitudes, and characteristics of the new vehicle purchased. The paper also uses information in the NVES data on the vehicle disposed of (if any), and the new vehicle purchased. See the data section in Sheldon and Dua (2018) for more details. 


\section{Vehicle Choice Model}

$\mathrm{U}$ sing the same methodology as Sheldon and Dua (2018), the sample is divided into subgroups based on consumer characteristics. The parameters for a mixed logit model are estimated for each subgroup. The mixed logit models the probability of consumer $n$ choosing vehicle i based on vehicle characteristics. All available makes, models and engine types are included as alternatives, where the engine type is an internal combustion engine (ICE), hybrid (HEV), PHEV or BEV. Recall PEVs include both PHEVs and BEVs (Sheldon and Dua 2018).

Table 1 shows the three variables used to divide the sample into subgroups:

1) Socio-economic: age, income, and education.

2) Pro-environmental attitude.
3) Residential location.

The parameters for a mixed logit model were estimated separately for each subgroup, for a total of 90 subgroups.

Table 2 shows the variables with fixed and random parameters in the mixed logit estimation. Each subgroup estimates utility function 1 first. If there is no valid convergence, which tends to be the case in subgroups without enough variation in certain parameters, the subgroups estimate utility function 2 which omits make (brand). As shown in Table 2, over two thirds (73 percent) of subgroups achieve a valid convergence using utility function 1 .

Utility function 1 includes indicators for makes (brands) and, as in Sheldon and Dua (2018), excludes ultra-luxury brands. It includes vehicle

Table 1. Subgroup categories.

Socio-economic group

Pro-enviro

\begin{tabular}{l|l|l}
\hline Age $<35 /$ Income $>\$ 70 \mathrm{~K} /$ College & No or missing & Metropolitan city \\
\hline Age $<35 /$ Income $>\$ 70 \mathrm{~K} /$ No college & Yes & Suburban community of a large city \\
\hline Age $<35 /$ Income $\leq \$ 70 \mathrm{~K} /$ College & & Small town or rural city \\
\hline Age $<35 /$ Income $\leq \$ 70 \mathrm{~K} /$ No college & & Farming area \\
\hline Age $35+/$ Income $>\$ 70 \mathrm{~K} /$ College & & Missing \\
\hline Age 35+/ Income $>\$ 70 \mathrm{~K} /$ No college & & \\
\hline Age 35 + / Income $\leq \$ 70 \mathrm{~K} /$ College & & \\
\hline Age $35+/$ Income $\leq \$ 70 \mathrm{~K} /$ No college & & \\
\hline Missing & &
\end{tabular}

Source: KAPSARC. 
Table 2. Utility function.

\begin{tabular}{|c|c|c|c|}
\hline $\begin{array}{l}\text { Utility } \\
\text { function }\end{array}$ & Fixed parameters & Random parameters & Number of subgroups \\
\hline 1 & Makes, bodies, HEV & $\begin{array}{l}\text { PHEV, BEV, (fuel economy*range* performance)/ } \\
\text { price }\end{array}$ & 73 \\
\hline 2 & Bodies, HEV & $\begin{array}{l}\text { PHEV, BEV, (fuel economy }{ }^{\star} \text { range }^{*} \text { performance)/ } \\
\text { price }\end{array}$ & 17 \\
\hline
\end{tabular}

As in Sheldon and Dua (2018), the first stage estimation excludes BEV and Tesla indicators. The second stage estimates the BEV and Tesla indicators, with the fuel economy-range-performance-price coefficient constrained at the estimate obtained from the first stage. This avoids collinearity issues between the BEV indicator and other attributes.

Source: KAPSARC.

characteristics and body type indicators (truck, convertible, coupe, full-size car, hatchback, minivan, SUV, and wagon). It also includes indicators for BEV, PHEV, and HEV. Performance is defined as horsepower over curb weight, and price as the manufacturer's suggested retail price (MSRP). For PEVs, the price is adjusted down by existing state, federal and manufacturer incentives.

There are two differences in this model relative to Sheldon and Dua (2018). First, in Sheldon and Dua (2018), the indicator for SUV is assumed to have a random parameter, whereas in this paper it has a fixed parameter. Here, the BEV and PHEV indicators are instead assumed to have random parameters. Attempting to assume random parameters on all three indicators makes the model numerically unstable for most subgroups and unable to achieve a valid convergence. Second, this paper includes separate choice sets for states with different subsidies. In Sheldon and Dua (2018) observations across these state levels are merged into one choice set with weighted prices. The model in this paper should more accurately capture consumer preferences for PEVs and price sensitivity, whereas Sheldon and Dua (2018) captures vehicle choice substitution patterns when PEVs are not available. 


\section{Policy Simulations}

$\mathrm{T}$ The study first estimates the mixed logit parameters separately for each of the 90 subgroups. It uses the estimates to predict the probability of consumers choosing the available vehicles at market prices. Predicted 2015 market shares for BEVs and PHEVs were 0.51 percent and 0.30 percent respectively, identical to the actual market shares. Without subsidies, the BEV market share would have fallen to 0.41 percent and 0.22 percent for PHEVs.

The study then divides the sample into 'subsidy groups.' These subsidy groups are different to the 90 consumer subgroups. The latter allows identification of heterogeneity by consumer preference. The different objectives of model estimation and policy simulation require different categorization. While categories such as educational attainment and environmental attitude help with model estimation, it would be politically unsavory for policymakers to vary subsidies according to these categories. Rather, identifiable sources of heterogeneity, such as income and household size, are useful for policy simulation.

The first set of subsidy groups is arranged by vehicle disposal and income, as shown in the top panel of Table 3. The NVES data also contain information on whether the consumer disposed of a vehicle when purchasing their new vehicle. The study measures the cost-effectiveness of subsidy programs according to vehicle disposal and income because these are observable variables that have formed the basis of past and current subsidy policies. The second set of subsidy groups are divided into geography and income, as shown in the middle panel of Table 3. 'Geography' refers to a residential metropolitan, suburban, rural, or

Table 3. Subsidy groups: income and vehicle disposal, geography, or monthly vehicle miles traveled (VMT).

Income and vehicle disposal

\begin{tabular}{l|l|l} 
Subsidy group & Description & 11.9 \\
\hline 1 & Disposed of small ICE, low income & 6.9 \\
\hline 2 & Disposed of large ICE, low income & 0.3 \\
\hline 3 & Disposed of HEV or PEV, low income & 4.6 \\
\hline 4 & Did not dispose of a vehicle, low income & 2.0 \\
\hline 5 & Did not own a vehicle, low income & 16.6 \\
\hline 7 & Disposed of small ICE, high income & 15.4 \\
\hline 8 & Disposed of large ICE, high income & 0.9 \\
\hline 9 & Disposed of HEV or PEV, high income & 9.1 \\
\hline 10 & Did not dispose of a vehicle, high income & 2.3 \\
\hline
\end{tabular}


Income and geography

\begin{tabular}{l|l|l} 
Subsidy group & Description & 6.0 \\
\hline 1 & Metropolitan, low income & 11.9 \\
\hline 2 & Suburban, low income & 12.2 \\
\hline 3 & Rural, low income & 2.2 \\
\hline 4 & Farming, low income & 9.2 \\
\hline 5 & Metropolitan, high income & 27.5 \\
\hline 7 & Suburban, high income & 15.7 \\
\hline 9 & Rural, high income & 2.7 \\
\hline
\end{tabular}

\section{Income and monthly VMT}

\begin{tabular}{l|l|l} 
Subsidy group & Description & 6.6 \\
\hline 1 & VMT $\leq 1000$, low income & 26.2 \\
\hline 2 & $1000<\mathrm{VMT} \leq 2000$, low income & 0.3 \\
\hline 3 & $2000<\mathrm{VMT} \leq 3000$, low income & 0.1 \\
\hline 4 & VMT>3000, low income & 3.3 \\
\hline 5 & VMT $\leq 1000$, high income & 53.0 \\
\hline 7 & $1000<\mathrm{VMT} \leq 2000$, high income & 0.1 \\
\hline 8 & $2000<\mathrm{VMT} \leq 3000$, high income & 0.1 \\
\hline 9 & VMT>3000, high income & 10.4 \\
\hline
\end{tabular}

The study assumes a monthly VMT of 1,116 miles (the sample average) for respondents who do not report it.

Source: KAPSARC. 
farming area. The third set of subsidy groups are categorized by monthly reported vehicle miles traveled (VMT) and income, as shown in the bottom panel of Table 3.

The policy simulations involve reducing PEV prices by varying subsidy amounts. State-level subsidies are set to zero to focus on federal policy. The first set of simulations start at 0 percent of current federal subsidies. They repeatedly increase by 5 percent for each subsidy group, up to a maximum of 300 percent. The second set of simulations start at $\$ 0$ and increase in $\$ 250$ increments for each subsidy group, up to a maximum of $\$ 20,000$. The first set of simulations preserves the existing federal policy's structure of assigning higher subsidies to PEVs with larger battery capacities. This reflects the policymakers' goal of reaching sufficient adoption levels of high range BEVs, to warrant 'economies of scale' in the production of larger batteries. The second set of simulations does not discriminate according to battery capacity. In this subsidy schedule, all consumers in a given subsidy group would receive the same subsidy for a BEV with a large battery capacity as a PHEV with a limited allelectric range. The second set of simulations is based on the notion that 'range-anxiety free' and thus 'easier to sell' PHEVs could result in a similar reduction in gasoline consumption as BEVs but at lower marginal cost, thus warranting an equal level of subsidization.

The last group of simulations involves increasing the BEV range by 100 miles. This set of simulations incorporate three scenarios: no subsidy, a fixed subsidy of $\$ 4,350$ to all BEV buyers, and a targeted subsidy of $\$ 7,925$ to only low-income BEV buyers. These subsidy levels were selected so that the total subsidy budget remains fixed at the estimated cost of the existing U.S. federal policy: approximately $\$ 592$ million.
Each iteration of the simulations predicts the number of PEVs sold nationally and the annual gasoline consumption of the new vehicle fleet. The fleet fuel consumption is the sales-weighted sum of individual fuel consumption. The individual fuel consumption is calculated by dividing each consumer's annual miles driven by the probability-weighted fuel economy of each consumer's new vehicle. The simulations predict the probability of the consumer choosing each vehicle alternative, and the weighted harmonic mean fuel economy of the alternatives is calculated using the choice probabilities as weights.

Once a schedule of PEV demand and gasoline consumption by subsidy level is obtained for each subsidy group, the cost-effective subsidy schedules are identified for a given budget constraint. The costeffective subsidy schedule is defined on two bases depending on the policy goal. The first definition is based on a subsidy schedule that aims to achieve maximum PEV sales. The second definition is one that minimizes annual gasoline consumption. Gasoline consumption depends on the vehicles' fuel economy and how many miles each vehicle is driven.

Tables 4 and 5 show the cost-effective subsidy schedules for the first and second sets of simulations, assuming a total budget of approximately $\$ 592$ million: the estimated cost of the existing U.S. federal policy. Due to the discrete nature of the subsidy simulations, in which subsidies increase by 5 percent or $\$ 250$ increments, it was not possible to simulate for a policy budget of exactly $\$ 592$ million. In all the simulated alternative policy scenarios, the cost-effective subsidies target lower income individuals whose annual incomes are under $\$ 70,000$. This is consistent with DeShazo, Sheldon, and Carson (2017), who find that lower income households are less likely to purchase PEVs in the absence of a rebate. 
Table 4. Cost-effective subsidy schedules, with subsidies varying by battery capacity.

Target by vehicle disposal

\begin{tabular}{|c|c|c|c|}
\hline Group no. & Subsidy group & Max PEVs & Min gas consumption \\
\hline 1 & Disposed of small ICE, low income & $205 \%$ & $205 \%$ \\
\hline 2 & Disposed of large ICE, low income & $210 \%$ & $215 \%$ \\
\hline 3 & Disposed of HEV or PEV, low income & $205 \%$ & $205 \%$ \\
\hline 4 & Did not dispose of a vehicle, low income & $210 \%$ & $205 \%$ \\
\hline 5 & Did not own a vehicle, low income & $205 \%$ & $175 \%$ \\
\hline 6 & Disposed of small ICE, high income & $0 \%$ & $0 \%$ \\
\hline 7 & Disposed of large ICE, high income & $0 \%$ & $0 \%$ \\
\hline 8 & Disposed of HEV or PEV, high income & $0 \%$ & $0 \%$ \\
\hline 9 & Did not dispose of a vehicle, high income & $0 \%$ & $0 \%$ \\
\hline 10 & Did not own a vehicle, high income & $0 \%$ & $0 \%$ \\
\hline 11 & Missing vehicle disposal and/or income field & $0 \%$ & $0 \%$ \\
\hline
\end{tabular}

Target by geography

\begin{tabular}{|c|c|c|c|}
\hline Group no. & Subsidy group & Max PEVs & Min gas consumption \\
\hline 1 & Metropolitan, low income & $200 \%$ & $0 \%$ \\
\hline 2 & Suburban, low income & $205 \%$ & $0 \%$ \\
\hline 3 & Rural, low income & $205 \%$ & $170 \%$ \\
\hline 4 & Farming, low income & $205 \%$ & $245 \%$ \\
\hline 5 & Metropolitan, high income & $0 \%$ & $0 \%$ \\
\hline 6 & Suburban, high income & $0 \%$ & $0 \%$ \\
\hline 7 & Rural, high income & $0 \%$ & $0 \%$ \\
\hline 8 & Farming, high income & $0 \%$ & $0 \%$ \\
\hline 9 & Missing location and/or income field & $0 \%$ & $0 \%$ \\
\hline
\end{tabular}


Target by monthly VMT

\begin{tabular}{|c|c|c|c|}
\hline Group no. & Subsidy group & Max PEVs & Min gas consumption \\
\hline 1 & VMT<=1000, low income & $205 \%$ & $210 \%$ \\
\hline 2 & $1000<\mathrm{VMT}<=2000$, low income & $205 \%$ & $200 \%$ \\
\hline 3 & $2000<\mathrm{VMT}<=3000$, low income & $200 \%$ & $225 \%$ \\
\hline 4 & VMT>3000, low income & $200 \%$ & $230 \%$ \\
\hline 5 & VMT $<=1000$, high income & $0 \%$ & $0 \%$ \\
\hline 6 & $1000<\mathrm{VMT}<=2000$, high income & $0 \%$ & $0 \%$ \\
\hline 7 & $2000<\mathrm{VMT}<=3000$, high income & $0 \%$ & $0 \%$ \\
\hline 8 & VMT>3000, high income & $0 \%$ & $0 \%$ \\
\hline 9 & Missing income & $0 \%$ & $0 \%$ \\
\hline
\end{tabular}

Note: Cost-effective subsidies are shown as a percent of current subsidies, which vary by battery capacity. Current subsidies (corresponding to 100 percent in the table) range between $\$ 2,500$ and $\$ 7,500$ per vehicle.

Source: KAPSARC.

Qualitatively, the results for the three policies targeting a particular source of observable heterogeneity (vehicle disposal, geography, or VMT) in Tables 4 and 5 are very similar. The cost-effective subsidy schedule in each case varies according to whether the goal is to maximize PEV market share or minimize gasoline consumption.

The top panels of Tables 4 and 5 show that, when targeting by vehicle disposal, the most effective use of subsidy money is to target low-income individuals, regardless of the vehicle they are disposing of. However, if the aim is to minimize gasoline consumption, the most cost-effective policy would be to attribute a smaller subsidy to low-income individuals who do not own a vehicle to dispose of, with a larger subsidy to low-income individuals who dispose of a large ICE.
The middle panels of Tables 4 and 5 show that policymakers have the scope to maximize PEV sales most efficiently by restricting subsidies to only low-income consumers, regardless of geography. The most cost-effective way for policymakers to minimize gasoline consumption is to eliminate subsidies for consumers residing in metropolitan and suburban areas, maintain them for those in rural areas, and increase them for those residing in farming areas. Residents of rural and farming areas, in particular, tend to have larger VMT compared to residents of metropolitan and suburban areas. Subsidizing PEVs in rural and farming areas results in lower gasoline consumption than subsidizing PEVs in metropolitan areas.

The bottom panels of Tables 4 and 5 show that policymakers have the scope to maximize PEV 
Table 5. Cost-effective subsidy schedules, with subsidies not varying by battery capacity.

Target by vehicle disposal

\begin{tabular}{|c|c|c|c|}
\hline Group no. & Subsidy group & Max PEVs & Min gas consumption \\
\hline 1 & Disposed of small ICE, low income & $\$ 13,500$ & $\$ 13,000$ \\
\hline 2 & Disposed of large ICE, low income & $\$ 13,500$ & $\$ 14,250$ \\
\hline 3 & Disposed of HEV or PEV, low income & $\$ 13,250$ & $\$ 13,000$ \\
\hline 4 & Did not dispose of a vehicle, low income & $\$ 13,250$ & $\$ 13,500$ \\
\hline 5 & Did not own a vehicle, low income & $\$ 13,250$ & $\$ 11,750$ \\
\hline 6 & Disposed of small ICE, high income & $\$ 0$ & $\$ 0$ \\
\hline 7 & Disposed of large ICE, high income & $\$ 0$ & $\$ 0$ \\
\hline 8 & Disposed of HEV or PEV, high income & $\$ 0$ & $\$ 0$ \\
\hline 9 & Did not dispose of a vehicle, high income & $\$ 0$ & $\$ 0$ \\
\hline 10 & Did not own a vehicle, high income & $\$ 0$ & $\$ 0$ \\
\hline 11 & Missing vehicle disposal and/or income field & $\$ 0$ & $\$ 0$ \\
\hline
\end{tabular}

Target by geography

\begin{tabular}{|c|c|c|c|}
\hline Group no. & Subsidy group & Max PEVs & Min gas consumption \\
\hline 1 & Metropolitan, low income & $\$ 13,000$ & $\$ 0$ \\
\hline 2 & Suburban, low income & $\$ 13,000$ & $\$ 0$ \\
\hline 3 & Rural, low income & $\$ 13,250$ & $\$ 13,000$ \\
\hline 4 & Farming, low income & $\$ 13,250$ & $\$ 17,750$ \\
\hline 5 & Metropolitan, high income & $\$ 0$ & $\$ 0$ \\
\hline 6 & Suburban, high income & $\$ 0$ & $\$ 0$ \\
\hline 7 & Rural, high income & $\$ 0$ & $\$ 0$ \\
\hline 8 & Farming, high income & $\$ 0$ & $\$ 0$ \\
\hline 9 & Missing location and/or income field & $\$ 0$ & $\$ 0$ \\
\hline
\end{tabular}


Target by monthly VMT

\begin{tabular}{|c|c|c|c|}
\hline Group no. & Subsidy group & Max PEVs & Min gas consumption \\
\hline 1 & VMT<=1000, low income & $\$ 13,000$ & $\$ 13,500$ \\
\hline 2 & $1000<\mathrm{VMT}<=2000$, low income & $\$ 13,250$ & $\$ 13,000$ \\
\hline 3 & $2000<\mathrm{VMT}<=3000$, low income & $\$ 13,000$ & $\$ 14,500$ \\
\hline 4 & VMT>3000, low income & $\$ 13,000$ & $\$ 15,250$ \\
\hline 5 & VMT $<=1000$, high income & $\$ 0$ & $\$ 0$ \\
\hline 6 & $1000<\mathrm{VMT}<=2000$, high income & $\$ 0$ & $\$ 0$ \\
\hline 7 & $2000<\mathrm{VMT}<=3000$, high income & $\$ 0$ & $\$ 0$ \\
\hline 8 & VMT $>3000$, high income & $\$ 0$ & $\$ 0$ \\
\hline 9 & Missing income & $\$ 0$ & $\$ 0$ \\
\hline
\end{tabular}

Source: KAPSARC.

market share by subsidizing all low-income consumers. However, if the aim is to minimize gasoline consumption, this would require larger subsidies for low-income individuals who drive over 2,000 miles per month.

Tables 6 and 7 show BEV and PHEV market shares and total fleet annual gasoline consumption for various subsidy policies. The tables detail the total cost of each policy, the cost per additional PEV and the cost per gallon of gasoline reduction resulting from the policy. The cost per gallon of gasoline reduction assumes a vehicle life of ten years. The first column shows predicted market shares if existing state and federal subsidies were eliminated. The second column shows the metrics for the current set of federal subsidies, assuming that all eligible vehicles receive the subsidies.
The results imply that state and federal subsidies contributed to 22 percent of PEV sales in the 2015 model year, and federal subsidies alone accounted for 17 percent of all PEV sales. The 22 percent figure is lower than the 27 percent found in Sheldon and Dua (2018). This difference is due to two differences in the vehicle choice models, as discussed previously. The 22 figure is also lower than the 30 percent found to be attributable to the federal tax credit by Tal and Nicholas (2016) and the 40 percent found by Li et al. (2017). The estimates in Tal and Nicholas (2016), however, are for eleven states and are not nationally representative, which could partly explain the difference. Li et al. (2017) estimate that 40 percent of the 40 percent was due to feedback loops. Without these feedback loops, the federal tax credit would account for 24 percent of national PEV sales, much closer to the 17 percent 
estimated in this study. The findings by Li et al. (2017) suggest that this study's absolute estimates would be higher if feedback loops were factored in. Nevertheless, the feedback loops would likely not change the differences in effectiveness we find across PEV subsidy policies.

The remaining columns of Tables 6 and 7 show metrics for policies that, with a budget of approximately $\$ 592$ million, result in either maximum PEV market share or minimum gasoline consumption by targeting rebates by income and vehicle disposal, geography, or monthly VMT. These correspond to the cost-effective subsidy schedules shown in Tables 4 and 5.

According to the estimates in Tables 6 and 7, the existing federal incentive policy costs $\$ 35,601$ per additional PEV. This is larger than the approximate figure of $\$ 30,000$ established by DeShazo, Sheldon, and Carson (2017). The difference between the two figures is likely due to the fact that the simulations in this study include federal subsidies of up to $\$ 7,500$ per vehicle and do not include state subsidies, whereas DeShazo, Sheldon, and Carson (2017) only analyze California's state-level incentive. This

Table 6. Market shares and policy metrics for various subsidy policies, with subsidies varying by battery capacity.

\section{Target by disposal Target by geography Target by VMT}

\begin{tabular}{|c|c|c|c|c|c|c|c|c|}
\hline Subsidy & None & Current & $\begin{array}{l}\text { Max } \\
\text { PEVs }\end{array}$ & $\begin{array}{l}\text { Min gas } \\
\text { consumption }\end{array}$ & $\begin{array}{l}\text { Max } \\
\text { PEVs }\end{array}$ & $\begin{array}{l}\text { Min gas } \\
\text { consumption }\end{array}$ & $\begin{array}{l}\text { Max } \\
\text { PEVs }\end{array}$ & $\begin{array}{l}\text { Min gas } \\
\text { consumption }\end{array}$ \\
\hline BEV share & $0.41 \%$ & $0.49 \%$ & $0.67 \%$ & $0.67 \%$ & $0.67 \%$ & $0.67 \%$ & $0.67 \%$ & $0.66 \%$ \\
\hline PHEV share & $0.22 \%$ & $0.27 \%$ & $0.25 \%$ & $0.25 \%$ & $0.26 \%$ & $0.23 \%$ & $0.25 \%$ & $0.25 \%$ \\
\hline $\begin{array}{l}\text { Annual gas consumption } \\
\text { (billions of gallons) }\end{array}$ & 7.1518 & 7.1445 & 7.1370 & 7.1370 & 7.1369 & 7.1349 & 7.1369 & 7.1373 \\
\hline $\begin{array}{l}\text { Total cost } \\
\text { (millions) }\end{array}$ & & $\$ 592$ & $\$ 602$ & $\$ 601$ & $\$ 602$ & $\$ 601$ & $\$ 604$ & $\$ 586$ \\
\hline $\begin{array}{l}\text { Cost per additional } \\
\text { PEV }\end{array}$ & & $\$ 35,601$ & $\$ 16,378$ & $\$ 16,414$ & $\$ 16,241$ & $\$ 18,108$ & $\$ 16,258$ & $\$ 16,301$ \\
\hline $\begin{array}{l}\text { Cost per gallon of } \\
\text { gas savings }{ }^{*}\end{array}$ & & $\$ 8.182$ & $\$ 4.075$ & $\$ 4.069$ & $\$ 4.043$ & $\$ 3.554$ & $\$ 4.062$ & $\$ 4.058$ \\
\hline
\end{tabular}

Note: This table displays BEV and PHEV market shares and total annual gasoline consumption by the fleet for various subsidy policies. The total cost of each policy is shown along with the cost per additional PEV and the cost per gallon of gasoline reduction resulting from the policy. The latter assumes a vehicle life of ten years. The first column shows predicted market shares if existing state and federal subsidies were eliminated. The second column shows the metrics for the current set of federal subsidies, assuming that every eligible vehicle received the subsidies. The total budget of the current federal policy is approximately $\$ 592$ million. The remaining columns show metrics for policies that, with a budget of approximately $\$ 592$ million, result in either maximum PEV market share or minimum gasoline consumption by targeting rebates by income and vehicle disposal, geography, or monthly VMT. These correspond to the cost-effective subsidy schedules shown in Table 4. 
Table 7. Market shares and policy metrics for various subsidy policies, with subsidies not varying by battery capacity.

Target by disposal Target by geography Target by VMT

\begin{tabular}{|c|c|c|c|c|c|c|c|c|}
\hline Subsidy & None & Current & $\begin{array}{l}\text { Max } \\
\text { PEVs }\end{array}$ & $\begin{array}{l}\text { Min gas } \\
\text { consumption }\end{array}$ & $\begin{array}{l}\text { Max } \\
\text { PEVs }\end{array}$ & $\begin{array}{l}\text { Min gas } \\
\text { consumption }\end{array}$ & $\begin{array}{l}\text { Max } \\
\text { PEVs }\end{array}$ & $\begin{array}{l}\text { Min gas } \\
\text { consumption }\end{array}$ \\
\hline BEV share & $0.41 \%$ & $0.49 \%$ & $0.49 \%$ & $0.49 \%$ & $0.49 \%$ & $0.52 \%$ & $0.49 \%$ & $0.49 \%$ \\
\hline PHEV share & $0.22 \%$ & $0.27 \%$ & $0.45 \%$ & $0.45 \%$ & $0.45 \%$ & $0.39 \%$ & $0.45 \%$ & $0.45 \%$ \\
\hline $\begin{array}{l}\text { Annual gas consumption } \\
\text { (billions of gallons) }\end{array}$ & 7.1518 & 7.1445 & 7.1368 & 7.1369 & 7.1366 & 7.1352 & 7.1368 & 7.1368 \\
\hline $\begin{array}{l}\text { Total cost } \\
\text { (millions) }\end{array}$ & & $\$ 592$ & $\$ 595$ & $\$ 592$ & $\$ 593$ & $\$ 597$ & $\$ 594$ & $\$ 590$ \\
\hline $\begin{array}{l}\text { Cost per additional } \\
\text { PEV }\end{array}$ & & $\$ 35,601$ & $\$ 15,338$ & $\$ 15,366$ & $\$ 15,152$ & $\$ 17,031$ & $\$ 15,212$ & $\$ 15,218$ \\
\hline $\begin{array}{l}\text { Cost per gallon of } \\
\text { gas savings* }\end{array}$ & & $\$ 8.182$ & $\$ 3.982$ & $\$ 3.972$ & $\$ 3.919$ & $\$ 3.611$ & $\$ 3.954$ & $\$ 3.949$ \\
\hline
\end{tabular}

Note: This table displays BEV and PHEV market shares and total annual gasoline consumption by the fleet for various subsidy policies. The total cost of each policy is shown along with the cost per additional PEV and the cost per gallon of gasoline reduction resulting from the policy. The latter assumes a vehicle life of ten years. The first column shows predicted market shares if existing state and federal subsidies were eliminated. The second column shows the metrics for the current set of federal subsidies, assuming that every eligible vehicle received the subsidies. The total budget of the current federal policy is approximately $\$ 592$ million. The remaining columns show metrics for policies that, with a budget of approximately $\$ 592$ million, result in either maximum PEV market share or minimum gasoline consumption by targeting rebates by income and vehicle disposal, geography, or monthly VMT. These correspond to the cost-effective subsidy schedules shown in Table 5.

Source: KAPSARC.

study's results suggest that the cost of existing incentives per additional PEV purchase is unsuitably high, with the cost per gallon of gasoline savings at $\$ 8.18$ per gallon.

Targeted subsidy schedules, such as those shown in Tables 4 and 5, would be far cheaper than the existing federal policy, as illustrated by Table 6. The policy cost per additional PEV would fall from $\$ 35,601$ to $\$ 16,241$, and the cost per gallon of gasoline savings would decline from $\$ 8.18$ to $\$ 3.55$ per gallon when discriminating subsidies by battery size and targeting subsidies by income, vehicle disposal, geography or VMT. Without discriminating by battery size but with the same target subsidies, the policy cost is reduced further to $\$ 15,152$ per additional PEV and the cost per gallon of gasoline savings reduced to $\$ 3.61$, as shown in Table 7.

The major difference between the two sets of simulations (discriminating versus not discriminating by battery capacity) is that, in the former, the BEV share increases substantially as a result of the subsidy policies, while the PHEV share stays 
fairly flat. In contrast, in the latter, the BEV share stays fairly flat while the PHEV share increases substantially as a result of the subsidy policies. This is because policies that assign higher subsidies to PEVs with larger battery capacities effectively assign higher subsidies to BEVs and considerably lower subsidies to PHEVs, resulting in greater BEV uptake. However, when not discriminating by battery capacity, PHEV uptake is greater. A comparison between Tables 6 and 7 shows that consumers are more inclined to adopt PHEVs when subsidies do not discriminate by battery capacity. Table 7 shows that, when subsidies are equal across technologies, the subsidy policies tend to result in a lower cost per additional PEV. The most cost-effective route is to assign similar levels of subsidies to PHEVs and BEVs. This results in a similar reduction in gasoline consumption to assigning higher subsidies to BEVs, and at a lower marginal cost.

Table 8 shows simulation results for a 100-mile increase in BEV driving range, keeping the same vehicle price. It results in a BEV market share of 0.80 percent. On the other hand, a 100 -mile range increase in BEVs coupled with a fixed BEV subsidy amount of $\$ 4,350$ results in a BEV market share of 1.09 percent. The fixed subsidy leads to a $\$ 15,980$ cost per additional BEV and a cost per gallon of gasoline savings of $\$ 3.67$. This subsidy could account for 23 percent of BEV sales. It implies that improving the driving range of BEVs would significantly reduce the cost of even fixed subsidy schedules. As the market share for BEV increases, increasingly more consumers will get the subsidy. Thus, with improved BEV offerings policymakers are more likely to adopt targeted subsidy schedules to further improve the impact and cost-effectiveness of PEV support policies. A targeted subsidy of $\$ 7,925$, restricted to low-income individuals and for BEVs with an additional 100mile range, results in a cost of $\$ 9,712$ per additional BEV and a cost per gallon of gasoline savings of \$2.41. This subsidy could account for 32.5 percent of BEV sales.

Table 8. Market shares and policy metrics for various subsidy policies, where each BEV model's range increases by 100 miles.

\begin{tabular}{|c|c|c|c|}
\hline Subsidy & None & Fixed subsidy & Targeted subsidy \\
\hline BEV share & $0.80 \%$ & $1.09 \%$ & $1.28 \%$ \\
\hline PHEV share & $0.21 \%$ & $0.21 \%$ & $0.21 \%$ \\
\hline Annual gas consumption (billions of gallons) & 7.1306 & 7.1144 & 7.1061 \\
\hline Total cost (millions) & & $\$ 595$ & $\$ 591$ \\
\hline Cost per additional BEV & & $\$ 15,980$ & $\$ 9,712$ \\
\hline Cost per gallon of gas savings & & $\$ 3.675$ & $\$ 2.41$ \\
\hline
\end{tabular}

Note: This table displays BEV and PHEV market shares and total annual gasoline consumption by the fleet for various subsidy policies, where each BEV model's range increases by 100 miles. The table shows the total cost of each policy, the cost per additional BEV and the cost per gallon of gasoline reduction resulting from the policy. The latter assumes a vehicle life of ten years. The first column shows predicted market shares for the zero subsidy case. The second column shows the metrics for a fixed BEV subsidy of $\$ 4,350$ to each BEV buyer. The third column shows metrics for subsidy policy targeted by income, with a targeted subsidy of $\$ 7,925$ to low-income individuals only.

Source: KAPSARC. 


\section{Discussion}

$\mathrm{T}$ The subsidies in these analyses and simulations are applied at the point of sale. Studies have shown that consumer responsiveness to incentives varies according to when the incentive is applied. An income tax credit rather than a rebate, for example, may result in lower uptake (Gallagher and Muehlegger 2011). The existing federal policy administers PEV subsidies through income tax credit, whereby any amount of federal income tax over $\$ 7,500$ owed for that tax year will be credited to the consumer, up to a maximum of $\$ 7,500$. This credit does not roll over to the following year. The results of this study suggest that policymakers have the scope to direct subsidies towards lower income consumers to improve the cost-effectiveness of the federal PEV incentive policy. It is unlikely that lower-income households' taxable income would be high enough to qualify for such large subsidies in the form of tax credits. Therefore, it is likely that such subsidies would be implemented at the point of sale, for example as a rebate.

Assigning high subsidies to lower income consumers could distort the secondary market. Currently, no empirical evidence exists of such distortions in markets with progressive PEV incentives, such as California's Replace your Ride program in which some low-income consumers are eligible for incentives exceeding $\$ 10,000$ (Pierce and DeShazo 2018). However, it is possible for highly subsidized consumers to purchase a new PEV and sell it on the secondary market for a higher price than he or she paid, thereby earning a profit. Policymakers could avoid such distortions by requiring subsidy recipients to pay back a portion of the subsidy upon transferring the PEV title if they sell the vehicle within a certain number of years of purchasing it. The subsidy to be paid back could decrease over time to reflect the vehicle's depreciation. Ideally, the subsidy due to be paid back should equal any potential secondary market profit.

There are potential difficulties of assigning a subsidy based on VMT, including the requirement for verifiable proof of VMT. This might be in the form of odometer readings taken over the course of standard oil changes and smog checks. If consumers with higher VMT are eligible for larger rebates, this could provide prospective PEV buyers with an incentive to intentionally increase VMT in the months or years before purchasing the PEV. Policymakers could request proof of VMT from a period no later than the date of the policy announcement, to avoid such strategic behavior. Alternatively, policymakers might choose to target VMT by proxy: by geography or another observable attribute correlated with VMT. 


\section{Conclusion}

sing a nationally representative sample of new vehicles purchased in the United States in 2015, this study estimates a vehicle choice model. A mixed logit is estimated separately for 90 subgroups of consumers to incorporate consumer heterogeneity, allowing preferences to vary by income, age, education, environmental attitudes, and geography. The estimates are then used to predict plug-in electric vehicle (PEV) market share and fleet gasoline consumption, according to various subsidy policies. Results suggest that existing federal incentives are unsuitably expensive and that policymakers have the scope to reduce costs by targeting incentives according to income, vehicle disposal, geography, and/or vehicle miles traveled. Such designs have the potential to improve policy cost-effectiveness by more than two-fold. These cost-effective designs involve restricting subsidies to lower income individuals, whose purchases are more likely to be additional.

Cost-effective subsidy schedules differ somewhat according to whether the policy goal is to maximize PEV market share or minimize gasoline consumption resulting from PEV adoption. If the goal is to maximize PEV market share, policymakers might choose to give the same subsidy to all low-income individuals. In contrast, to minimize gasoline consumption, policymakers have the scope to target subsidies at individuals who dispose of a large ICE vehicle, who reside in rural or farming areas, or who drive more than 2,000 miles per month. Preserving the current federal policy's assignment of larger subsidies for PEVs with larger battery capacities results in increased BEV adoption, while policies that do not discriminate by battery capacity result in increased PHEV adoption. Improvement in BEV driving range by 100 miles would improve the cost-effectiveness of a fixed BEV subsidy schedule to similar levels as the demographics-based subsidy schedule. With improvements in BEV driving range, coupled with targeted subsidy schedule, policymakers might be able to achieve more than a three-fold improvement in policy cost-effectiveness. 
DeShazo, JR, Tamara L Sheldon, and Richard T Carson. 2017. "Designing policy incentives for cleaner technologies: Lessons from California's plug-in electric vehicle rebate program." Journal of Environmental Economics and Management no. 84:18-43. https://doi. org/10.1016/j.jeem.2017.01.002

Gallagher, Kelly Sims, and Erich Muehlegger. 2011. "Giving green to get green? Incentives and consumer adoption of hybrid vehicle technology." Journal of Environmental Economics and management no. 61 (1):115. https://doi.org/10.1016/j.jeem.2010.05.004

Jin, L., S. Searle, and N. Lutsey. Evaluation of state-level U.S. electric vehicle incentives. The International Council on Clean Transportation 2014. Available from http://www.theicct.org/ evaluation-statelevel-us-electric-vehicle-incentives

Li, Shanjun, Lang Tong, Jianwei Xing, and Yiyi Zhou. 2017. "The market for electric vehicles: indirect network effects and policy design." Journal of the Association of Environmental and Resource Economists no. 4 (1):89133. https://doi.org/10.1086/689702

Pierce, Gregory, and JR DeShazo. 2018. "Design and Implementation of the Enhanced Fleet Modernization Plus Up Pilot Program: Lessons Learned from the San Joaquin Valley and South Coast Air Districts' First Year of Operation." https://doi.org/10.7922/G21834NP
Sheldon, Tamara L., J. R. DeShazo, and Richard T. Carson. 2017. "ELECTRIC AND PLUG-IN HYBRID VEHICLE DEMAND: LESSONS FOR AN EMERGING MARKET." Economic Inquiry no. 55 (2):695-713. doi: 10.1111/ecin.12416

Sheldon, Tamara L., and R. Dua. Gasoline Savings From Clean Vehicle Adoption. KAPSARC 2018. Available from https://www.kapsarc.org/wp-content/uploads/2018/01/ KS-2017-DP026-Gasoline-Savings-From-Clean-VehicleAdoption.pdf

Sierzchula, William, Sjoerd Bakker, Kees Maat, and Bert van Wee. 2014. "The influence of financial incentives and other socio-economic factors on electric vehicle adoption." Energy Policy no. 68:183-194. doi: https://doi. org/10.1016/j.enpol.2014.01.043

Tal, Gil, and Michael Nicholas. 2016. "Exploring the impact of the federal tax credit on the plug-in vehicle market." Transportation Research Record: Journal of the Transportation Research Board (2572):95-102. https:// doi.org/10.3141/2572-11 


\section{About the Team}

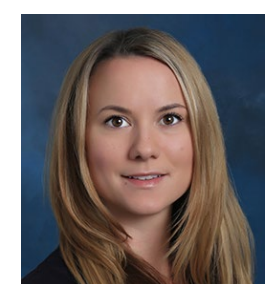

\section{Tamara Sheldon}

Tamara is a visiting researcher at KAPSARC and an assistant professor of economics in the Darla Moore School of Business at the University of South Carolina. Her research interests include environmental and energy economics and how these fields interact with public policy. She holds a Ph.D. in Economics from University of California, San Diego.

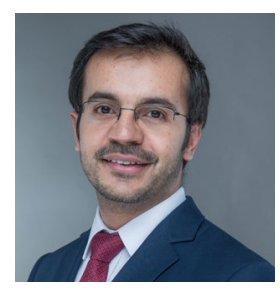

\section{Rubal Dua}

Rubal is a research fellow at KAPSARC, working on vehicle regulatory policy and shared mobility research using the consumer perspective. He holds a Ph.D. degree from KAUST, KSA, an M.S. degree from the University of Pennsylvania, USA and a B.Tech degree from IIT Roorkee, India.

\section{About the Project}

Promoting adoption of energy-efficient vehicles has become a key policy imperative in both developed and developing countries. Understanding the impact of various factors that affect adoption rates forms the backbone of KAPSARC's efforts in the light-duty vehicle demand field. These include (i) consumer-related factors - demographics, behavioral, psychographics; (ii) regulatory factors - policies, incentives, rebates, perks; and (iii) geo-temporal factors - weather, infrastructure, network effects. Our team is currently developing models at different levels of resolution: micro-level models using largescale data comprising of new car buyers' profiles, and macro level models using aggregated adoption data, to understand and project the effects of various factors at play for the adoption of energy-efficient vehicles. 
ANAPSARC

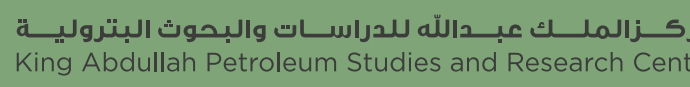

www.kapsarc.org 